\title{
Biofertilizers: Potential Candidate for Sustainable Agriculture
}

\author{
Monika $^{1^{*}}$, Shashikala ${ }^{2}$ and Leela Wati ${ }^{1}$ \\ ${ }^{1}$ Department of Microbiology, CCS Haryana Agricultural University, Hisar-125004, India \\ ${ }^{2}$ Department of Bio and Nano Technology, Guru Jambheshwar University of Science \& \\ Technology, Hisar-125004, India
}

*Corresponding author

\begin{abstract}
A B S T R A C T

\begin{tabular}{|l|}
\hline K e y w o r d s \\
Rhizobia, Plant \\
growth promotion, \\
Sustainable \\
agriculture, \\
Biofertlizers
\end{tabular}

\section{Introduction}

Imbalance in nitrogen $(\mathrm{N})$ cycling, nutritional status, physical and biological properties of soil, incidence of pests and diseases, fluctuating climatic factors and abiotic stresses are the interlinked contributing factors for reduced agricultural productivity. Agricultural sustainability, food security and energy renewability depends on a healthy and fertile soil. However, excessive use of chemical fertilizers for better agriculture productivity diminishes the soil fertility and is also harmful for human beings, animals and plants. A reversal of the decline in soil health is
\end{abstract}

\begin{abstract}
The use of chemical fertilizers in agriculture sector has gradually increased in recent past. Increase in demand of chemical fertilizers leads to increased market prices, market demand and consumption of chemical fertilizers which is not economically feasible for sustainable agriculture. Moreover, excessive use of chemical fertilizers to increase agriculture production leaving bad to worse impact on environment and human health. Hence, concept of using rhizobia as a biofertilizer is a promising source in terms of environment health and cost effectiveness. The use of biological nitrogen fixation (BNF) technology in the form of Rhizobium inoculants in grain legumes can be an alternative of expensive fertilizer, particularly for improving the production of food legumes in the country. The present review emphasized on biofertilizers mediated traits like plant growth and productivity, nutrient profile and plant protection from various serious plant pathogens. The knowledge gained from the literature appraised herein will help us to understand the physiology and various function of rhizobia.
\end{abstract}


and phosphorus. They have potential to increase the production of crop by improving yield and quantity. Such improvements includes production efficiency at given level of inputs and consequently reduce input level to achieve same yield. Reducing input level can help in resolving some core issues of sustainability like eutrophication of water resources caused by excessive use of phosphorus (P) and nitrogen fertilizers and also overcome the depletion of nonrenewable resources such as rock phosphate. To effective in addressing any of these concern microbial inoculant can use as biofertilizer in crop production. Rhizobium is one of the suitable microbial inoculant in terms of maintaining sustainability. In this context, there is an ongoing rigorous research worldwide with greater impetus to explore a wide range of biofertilizers. Biofertilizers, one of the important components of the sustainable agriculture are products containing living microorganisms which have the ability to mobilize nutritionally important elements from non usable to usable form through biological processes (Glazer and Nikado, 2007).

Biofertilizers have come to stay in Indian agriculture since last three decades in view of their cost effectiveness, contribution to crop productivity, soil sustainability and ecofriendly characters. Use of biofertilizers is one of the important components of integrated nutrient management as these are renewable source of plant nutrients to supplement the chemical fertilizers for sustainable agriculture.

Microorganisms possess novel traits like salinity tolerance, temperature tolerance, biological control of phytopathogens and insects along with normal plant growth promoting traits like phytohormone production, siderophore, 1-amino cyclopropane- 1-carboxylate (ACC), hydrogen cyanide $(\mathrm{HCN})$, and ammonia production, phosphate solubliization and potassium solubilization (Fig. 1 and 2). Hence, diverse symbiotic (Rhizobium, Bradyrhizobium and Mesorhizobium) microorganisms are now being used worldwide as bio-inoculants to promote plant growth, nitrogen fixation and development under various stresses and improve the soil fertility. The maximum productivity using symbiotic microorganismsdepend on crop, nodule number, nodule weight and the efficient strain of bacteria that survives in their root nodules which in turn are affected by supply or presence of macronutrients and micronutrients (Glick, 2012).

\section{Rhizobium-legume symbiosis}

The use of leguminous plants as green fertilizers was mostly based on their symbiotic nitrogen fixing ability. Legume crops meet their $\mathrm{N}$ requirement through symbiotic nitrogen fixation by forming root nodules with rhizobia, which in turn reduce the dependency of agricultural crops on fossil fuel-derived nitrogenous fertilizers. Additionally, biologically fixed $\mathrm{N}$ is bound in soil organic matter and thus much less is susceptible to soil chemical transformations and physical factors that lead to volatilization and leaching. Therefore, BNF has an important role in sustaining productivity of soils. The importance of biological nitrogen fixation in modern agricultural economy is exemplified by the large number of books and reviews published in recent years.

\section{Development of nodules on legume roots}

The basic process of nodulation can be arbitrarily divided into stages of nodule initiation, nodule invasion and bacteroid maturation followed by nodule senescence. In the absence of the host, free-living rhizobia are in their saprophytic phase. The legume host roots excrete specific compounds and 
flavonoids that induce active chemotaxis towards defined regions of the roots. In the infectible zone of roots, rhizobia attach to the root hair surface. The nodulation genes of infecting rhizobia after induction by flavonoids (Schulze and Kondorosi, 1998) produce nodulation (Nod) factors (Popp and Off, 2011) that cause characteristic curling and deformations of root hairs and cortical cell divisions in compatible host.

The rhizobia invade the root hair cell at the root hair tip by means of an infection thread and travel down to the root hair towards the underlying cortical cell layers through the inwardly growing tubular tunnel-like infection thread. It proceeds towards the newly developed primordium, formed by induction of mitotic activity in the root cortex due to Rhizobium-made diffusible Nod factors and subsequently develops into the nodule meristem. Bacterial invasion spreads from cell to cell by the continued growth of infection threads. In the root cortex, infection threads ramify, penetrate individual nodule cells and the infection droplet are formed. Rhizobia from such infection droplets are released into nodule tissue cells and then occupy an organelle-like cytoplasmic compartment, termed the "symbiosome" (Ivanova et al., 2012). Upon release from infection thread, the bacteroids multiply, enlarge and eventually occupy most of the volume of infected cell.

In the late symbiotic zone, the infected cells are completely filled with bacteroids. These bacteroids reduce atmospheric nitrogen by the action of the nitrogenase enzyme. Leghaemoglobin protein is synthesized in nodules that help to maintain the low oxygen tension necessary for effective nitrogen fixation. During the programmed senescence of nitrogen-fixing bacteroids, growth and division of bacteroids is stopped and subsequently it results in lysis of $\mathrm{N}_{2}$-fixing bacteroids (Upvardi and Poole, 2013).

\section{Plant growth promoting traits of rhizobia}

\section{Mechanisms of plant growth promotion}

PGPR mediated plant growth promotion occurs by the alteration of the whole microbial community in rhizosphere niche through the production of various substances. Generally, PGPR promote plant growth directly by either facilitating resource acquisition (nitrogen, phosphorus and essential minerals) or modulating plant hormone levels, or indirectly by decreasing the inhibitory effects of various pathogens on plant growth and development by acting as a biocontrol agents (Glick, 2012) and fixing nitrogen. Selecting root nodule bacteria that tolerate these conditions will ensure success in legume productivity and reduced problem with nutrient deficiency.

\section{Direct mechanisms}

\section{Nitrogen fixation}

Nitrogen $(\mathrm{N})$ is the most vital nutrient for plant growth and productivity. Soils which are generally deficient in nitrogen; the most important element in the metabolism of plants, usually result in low crop yield. Although, there is about $78 \% \mathrm{~N}_{2}$ in the atmosphere, it is unavailable to the growing plants. The atmospheric $\mathrm{N}_{2}$ is converted into plantutilizable forms by biological $\mathrm{N}_{2}$ fixation (BNF) which changes nitrogen to ammonia by nitrogen fixing microorganisms using a complex enzyme system known as nitrogenase (Mrkkovacki et al., 2001). In fact, BNF accounts for approximately two-thirds of the nitrogen fixed globally, while the rest of the nitrogen is industrially synthesized by the Haber-Bosch process. Biological nitrogen fixation occurs, generally at mild temperatures, by nitrogen fixing microorganisms, which are widely distributed in nature. Furthermore, BNF represents an economically beneficial and environmentally 
sound alternative to chemical fertilizers. Nitrogen fixing organisms include free-living aerobic Azotobacter, Beijernickia, Klebsiella and Paenibacillus, free living anaerobic Clostridium and Desulfovibrio, symbiotic rhizobia and Frankia, and associative Azospirillum (Bhattacharya and Jha, 2012). Rhizobia-legume symbiosis has been reported to provide well over half of the biological source of fixed nitrogen and is the primary source of fixed nitrogen in land based systems. Nodulation and nitrogenase activity have been employed as major traits for the evaluation of rhizobia-legume symbiosis and selecting potential strains of rhizobia.

\section{1-aminocyclopropane-1-carboxylic (ACC) deaminase}

ACC deaminase is a member of a large group of enzyme that utilizes vitamin B6 and is considered to be under tryptophan synthase family. Rhizobia have the ability to uptake ACC and convert it into $\alpha$-ketobutyrate and NH3. This is used as a source of carbon and nitrogen. Hence, on inoculation of rhizobia producing ACC deaminase, the plant ethylene levels are lowered and result in longer roots providing relief from stresses, such as heavy metals, pathogens, drought, radiation, salinity, etc. Strains, such as $R$. leguminosarumbv. viciae, $R$. hedysari, $R$. japonicum, $R$. gallicum, B. japonicum, B. elkani, M. loti and S. meliloti had been known to produce ACC deaminase (Duan et al., 2009; Glick, 2007). It had also been shown that the rhizobia producing ACC deaminase are also efficient nitrogen fixers. The structural gene of ACC deaminase in Mesorhizobium sp. is under the control of nif promoter (Nascimento et al., 2012) which generally controls the nif gene responsible for nitrogen fixation.

Ma et al., (2003) demonstrated ACC deaminase activity in several Rhizobium spp. (R. leguminosarum, $R$. gallicum, and $R$. hedysari). Despite the ability to breakdown ACC and use it as a nitrogen source, many of these strains presented different levels of ACC deaminase activity under free-living conditions. Duan et al., (2009) also reported that ACC deaminase activity ranged from 0.076 to $0.274 \mu \mathrm{mol} \alpha$ - ketobutyrate $/ \mathrm{mg}$ protein/h in Rhizobium. Khandelwal and Sindhu 2013 observed that $38.9 \%$ of rhizobial isolates were able to utilize ACC. Othman and Tamimi (2016) isolated rhizobial isolates from chickpea and observed that $15 \%$ of rhizobial isolates utilized ACC. Chaudhary and Sindhu (2015) screened Mesorhizobium isolates for ACC utilization and observed that two isolates showed significant growth on ACC supplemented plates.

\section{Phosphate solubilizers}

Phosphorus $(\mathrm{P})$, the second important plant growth-limiting nutrient after nitrogen, is abundantly available in soils in both organic and inorganic forms (Khan et al., 2009). Despite of large reservoir of $\mathrm{P}$, the amount of available forms to plants is generally low. This low availability of phosphorous to plants is because the majority of soil $\mathrm{P}$ is found in insoluble forms, while the plants absorb it only in two soluble forms, the monobasic and the diabasic ions (Bhattacharyya and Jha, 2012). The insoluble $P$ is present as an inorganic mineral such as apatite or as one of several organic forms including inositol phosphate (soil phytate), phosphomonesters, and phosphotriesters (Glick, 2012).

Organisms coupled with phosphate solubilizing activity, often termed as phosphate solubilizing microorganisms (PSM), may provide the available forms of $\mathrm{P}$ to the plants, phosphate-solubilizing bacteria (PSB) are considered as promising biofertilizers since they can supply plants with $\mathrm{P}$ from sources. Bacterial genera like Azotobacter, Bacillus, Beijerinckia, 
Burkholderia, Enterobacter, Erwinia, Flavobacterium, Microbacterium, Pseudomonas, Rhizobium and Serratia are reported as the most significant phosphate solubilizing bacteria (Bhattacharyya and Jha, 2012). Typically, the solubilization of inorganic phosphorus occurs as a consequence of the action of low molecular weight organic acids which are synthesized by various soil bacteria (Zaidi et al., 2009). Conversely, the mineralization of organic phosphorus occurs through the synthesis of a variety of different phosphatases, catalyzing the hydrolysis of phosphoric esters (Glick, 2012). Importantly, phosphate solubilization and mineralization can coexist in the same bacterial strain.

Alikhani et al., (2006) evaluated a total of 446 rhizobial isolates, isolated from agricultural land of Iran for phosphate solubilization by the formation of visible dissolution halos on agar plates and found that 198 (44\%) and 341 (76\%) of the isolates solubilized $\mathrm{Ca} 3$ (PO4)2(TCP) and inositol hexaphosphate (IHP), respectively and concluded that in addition to their beneficial nitrogen fixing activity with legumes, rhizobia can improve plant phosphate nutrition by mobilizing inorganic and organic phosphate.

Sridevi and Mallaiah (2007) examined fortysix Rhizobium isolates from legume root and stem nodules of various plants for their phosphate-solubilizing ability on Pikovskaya's agar medium. Rhizobium isolates from root nodules of Cassia absus, Vigna trilobata and three strains from Sesbaniasesban showed zone of tricalcium phosphate (TCP) solubilization. Marraet al., (2013) evaluated ability of inoculant strains for tropical legumes to solubilise inorganic phosphates of low solubility that are found in tropical soils. Four of the strains were used as inoculants for cowpeas (Vigna unguiculata) (Bradyrhizobium sp. UFLA 03-84; Bradyrhizobium elkani INPA 03-11B and
Bradyrhizobium japonicum BR3267) or for common beans (Phaseolus vulgaris) (Rhizobium tropici CIAT 899T). Rhizobium etli UFLA 02-100 and Rhizobium leguminosarum $316 \mathrm{C} 10$ a were compared for phosphate solublization. The strains CIAT 899 and UFLA 02-100 were the only legume nodulating rhizobial strains able to solubilise different phosphate sources i.e. CaHPO4, $\mathrm{Al}\left(\mathrm{H}_{2} \mathrm{PO}_{4}\right)_{3}$ or $\mathrm{FePO}_{4 \cdot 2} \mathrm{H}_{2} \mathrm{O}$. Jadhav (2013) isolated rhizobia of soybean RBS 02 having dual potential of nitrogen fixation and phosphate solubilization, that can be exploited as good fertilizer. Waheed et al., (2014) isolated seven rhizobial strains from pea crop grown in Swabi field. Among seven strains of Rhizobium only four strains were competent to solubilize phosphate and phosphorus solublised measured in the range of $18-24 \mu \mathrm{g}$ ml-1. Singh et al., (2014) observed that $70 \%$ of isolated rhizobial strains showed phosphorous solubilization and phosphrous solubilization index ranged between 2.2 to 4.1 on Pikovskaya's agar medium.

\section{Ammonia production}

Ammonia produced by bacteria is taken up by plants as a source of nitrogen for their growth. Several process are there by which ammonia can be produced such as nitrite ammonification, degradation of various amino acids to produce biogenic amines as well as ammonia deamination, and the urease mediated hydrolytic degradation of urea. This form of ammonia cannot be used by plants but may be available through biological nitrogen fixation process (Ozgual and Ozgual, 2007, Nagoma et al., 2012). Rhizobium is the most well-known bacterial species that acts as the primary symbiotic nitrogen fixer. Inoculation with such bacteria enhances plant growth as a result of their ability to fix nitrogen to ammonia making it an available nutrient for plant growth. There are various reports about ammonia production. Like, Joseph et al., 
(2007) reported ammonia production in $95 \%$ of isolates of Bacillus followed by Pseudomonas (94.2\%), Rhizobium (74.2\%) and Azotobacter (45\%). Yadav et al., (2010) reported that all strains of Pseudomonas produced ammonia. The assessment of plant growth promotion activities of six bacterial isolates using Zea mays was carried out and they observed that all the six isolates produced ammonia (Marques et al., 2010). Singh et al., (2012) isolated 25 rhizobial isolates from rhizospheric soil and tested them for ammonia excretion. Among test isolates $66 \%$ of isolates were found to be positive for ammonia production. Nagoma et al., (2013) observed ammonia production in 50 isolates out of which only seven bacterial isolates were able to produce ammonia while one $S$. maltophiliaKC010525 was unable to produce ammonia. Similarly, Nagoma et al., (2014) isolated twenty three rhizobial isolates from chick pea plant and they reported that eleven bacterial isolates were able to produce ammonia while twelve isolates were unable to do so.

\section{Phytohormone production}

Phytohormones are the substances that stimulate plant growth at lower/equal to micromolar concentrations. These include indole-3-acetic (IAA) acid (auxin), cytokinins, gibberellins and abscisic acid. Indole-3-acetic acid (IAA) is the foremost phytohormone that accelerates plant growth and development by improving root/shoot growth and seedling vigor. IAA is involved in cell division, differentiation and vascular bundle formation and an essential hormone for nodule formation. It has been estimated that $80 \%$ of bacteria isolated from the rhizosphere can produce IAA (Wani et al., 2008; Santner et al., 2006; Spaepen et al., 2007; Spaepen et al., 2011). IAA production in Rhizobium takes place via indole-3-pyruvic acid and indole-3acetic aldehyde pathway. On inoculation of $R$. leguminosarum bv. viciae, 60-fold increase in IAA was observed in the nodules of vetch roots (Tsakelova et al., 2006; Tsakelova et al., 2005; Bhattacharya and Jha 2012). Bhattacharyya and Basu (1997) reported that Rhizobium sp. isolated from the root nodules of Desmodium gangeticum produced a high amount of indole acetic acid (IAA) from Ltryptophan in culture. Ghosh and Basu (2006) reported that mature root nodules of Phaseolus mungo contained higher amount of indole acetic acid (IAA) than non-nodulated roots. The broth supplemented with precursor, Ltryptophan, produced high amount of IAA. Roy and Basu (2004) reported that Rhizobium $s p$. isolated from Clitoriaternatea L. produced a high amount of IAA (16.4 $\mu \mathrm{g} \mathrm{mL}-1)$ from tryptophan in an unsupplemented basal medium. Datta and Basu, 2000 isolated twelve rhizobial isolates from the root nodules of a leguminous pulse-yielding shrub, Cajanus cajan that are found to produce high amounts (99.7 flg/ml) of indole acetic acid (lAA) during growth in basal medium supplemented with L-tryptophan.

Sridevi and Mallaiah (2007) isolated twenty six Rhizobium strains from root nodule of Sesbania sesban (L.) and they reported that all were IAA producers. IAA production has also been reported in rhizobia isolated from Vigna mungo (Mandal et al., 2007). The ability to synthesize phytohormone is widely distributed among plant-associated bacteria, $80 \%$ of the bacteria isolated from plant rhizosphere produce IAA. Anjum et al., (2011) isolated thirty five isolates from mungbean root nodules and screened these rhizobial isolates for IAA production in basal medium containing $0.01 \%$ tryptophan. All the isolates varied in IAA production abilities. IAA production in the isolates ranged between 41$70 \mu \mathrm{g}$ ml-1. Kumar and Ram 2013 evaluated the production of indole acetic acid by Rhizobium isolates from Vigna trilobata (L) Verdc. 
Fig.1 Mechanisms for plant growth promotion

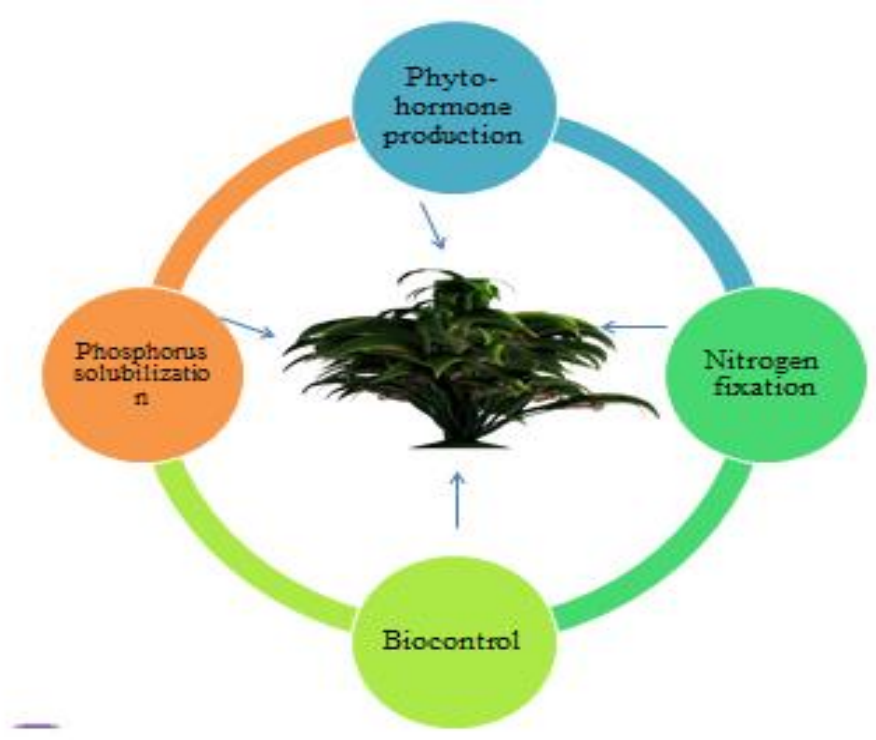

Fig.2 Indirect mechanism of biocontrol

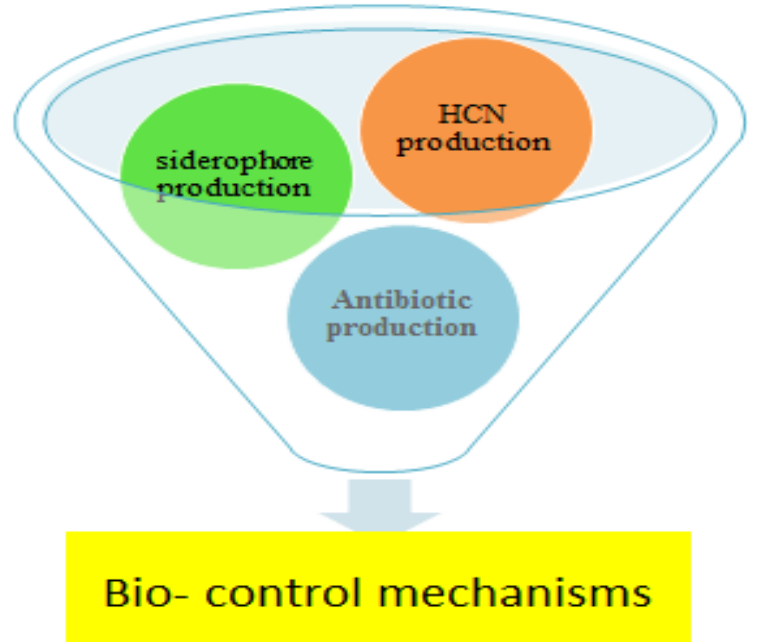

All the five isolates initiated IAA production immediately after inoculation and maximum was produced at $72 \mathrm{~h}$ in YEM broth and showed a decline afterwards. Maximum amount of IAA was produced $(92.6 \mu \mathrm{g} / \mathrm{ml})$ in isolate- 3 at $72 \mathrm{~h}$ of incubation. Ghosh et al., (2015) isolated Rhizobium undicola N 37 from root nodule of aquatic medicinal legume Neptunia oleracea Lour. They compared the IAA production in root and root nodule and they observed that IAA production and metabolism was more in root nodule as compared to root where no detectable amount of IAA found. 


\section{Indirect growth promotions}

There are many indirect ways through which rhizobia act as plant growth promoters with their biocontrol properties and induction of systemic resistance against phytopathogens and insect pests. PGP organisms have the ability to produce many active principles for biocontrol of various phytopathogens with antibiosis production. This includes (1) production of antibiotics such as 2,4-diacyetyl phloroglucinol (DAPG), kanosamine, phenazine-1-carboxylic acid, pyoluteorin, neomcycin A, pyrrolnitrin, pyocyanin and viscosinamide. Among them, DAPG is important since it has a broad spectrum antibacterial, antifungal and antihelminthic activity; (2) secretion of siderophores enabling iron uptake depriving the fungal pathogens in the vicinity; (3) production of low molecular weight metabolites such as hydrocyanic acid ( $\mathrm{HCN})$ which inhibits electron transport and hence disruption of energy supply to the cells; (4) production of lytic enzymes such as chitinase, $\beta-1,3$ glucanase, protease and lipase which lyse the pathogenic fungal and bacterial cell walls; (5) successfully competes for nutrients against phytopathogens and thereby occupies the colonizing site on root surface and other plant parts and (6) induces systemic resistance in plants by any of the metabolites mentioned above or by the inducting the production of phenyl alanine lyase, antioxidant enzymes such as peroxidase, polyphenol oxidase, superoxide dismutase, catalase, lipoxygenase and ascorbate peroxidase and also by phytoalexins and phenolic compounds in plant cells (Reddy, 2013).

\section{Siderophore formation}

Iron is the fourth abundant element on earth crust. Despite its relative abundance and its metabolic value to most organisms, it can be a difficult nutrient to obtain. Under aerobic environments, iron exists as insoluble hydroxides and oxyhydroxides, which are not accessible to both plants and microbes (Arora et al., 2001). Generally bacteria have the ability to synthesize low molecular weight compounds termed as siderophores capable of sequestering $\mathrm{Fe} 3+$. Rhizobia have been reported to produce a number of siderophores. These include rhizobactin, citrate anthranilate, catechol, rhizobactin. Siderophore production in iron stress conditions provide an added advantage, resulting in exclusion of pathogen due to iron starvation condition. These siderophores are known to have high affinity for $\mathrm{Fe} 3+$ and thus make the iron available for plants. Bacterial siderophores and other chelating metabolites are assumed to serve as major sources of plant available $\mathrm{Fe}$ in the rhizosphere and numbers of plants are able to use bacterial iron siderophore complexes as a source of iron from soil to meet the iron requirement (Neilands, 1981). Furthermore, the plant $\mathrm{Fe}$ acquisition can be enhanced by the use of microorganisms, which are able to produce chelating compounds under iron deficient conditions. Generally, each of rhizobial species is capable of producing one siderophore. Different strains of Rhizobium and Bradyrhizobium are able to produce siderophore for $\mathrm{Fe} 3+$ chelation in iron deficient environment (Glick, 1995; Glick, 2012).

Siderophores act as a growth inhibitor for various phytopathogenic fungi such as Phytopathora parasitica, Phythiumultimum, Fusarium oxysporum and Scleritinia sclerotiotrum. Arora et al., (2001) reported that out of twelve isolates of Rhizobium melliloti, which were obtained from medicinal plant, Mucuna pruriens, only two were able to produce siderophore. They also reported that these two isolates were able to inhibit a widely occurring plant pathogen, Macrophomina phaseolina and enhanced the percentage of seed germination, nodule 
number and nodule fresh weight of infected groundnut plants. Four rhizobia strains out of seven isolated from pea plant were siderphore positive (Waheed et al., 2014).

Alikhani and Yakhchali, (2009) found that $86 \%$ of rhizobial isolates obtained from different crop wheat, alfalfa and corn were siderophore positive. Rhizobium leguminosarum ATCC 14479 was investigated for the production for siderophore and it was determined that this strain produced a hydroxamate type siderophore under iron deficient conditions (Wright, 2010).

Verma et al., (2011) obtained twelve rhizobial strains form different leguminous plants and compared CAS assay of different strains with standard Rhizobium meliloti strain. Three isolates out of twelve showed halo zone formation (orange yellow colour) against blue medium. A fast-growing Rhizobium strain BICC 651 was isolated from a nodule produced on root of chickpea (Cicer arietinum L.) plant grown in the Experimental Farm of West Bengal, India. The strain produced a catechol type siderophore (Datta and Chakrabartty, 2014).

\section{HCN production}

$\mathrm{HCN}$ is the secondary metabolite produced by several microorganisms, has deleterious effect on the growth of some microbes. Some rhizospheric microorganisms have been shown to protect their host plants through the inhibition of growth of plant pathogens by $\mathrm{HCN}$ production.

Alikhani and Yakhchali (2009) examined 446 rhizobial isolates belonging to different species of rhizobia for $\mathrm{HCN}$ production and found that $7 \%$ of rhizobial isolates produced hydrogen cyanide. Wright (2010) obtained 123 rhizobial isolates, out which $33 \%$ rhizobial isolates were able to produce $\mathrm{HCN}$. Nithyakalyani et al., (2016) isolated eight rhizobial strains from Arachis hypogaea root nodule to investigate their plant growth promoting traits and found that all rhizobial isolates turned filter paper strips colour to orange red. Adnan et al., (2016) isolated 567 isolates from the root nodules of various summer legumes including Glycine max (Soybaen), Vigna radiata (Mung bean), Vigna unguiculata (Cowpea), Susbenia grandiflora (Sesbania) and Cymposis tetragonoloba (Guar) and found that only 9\% of rhizobial isolates were able to produce orange red colouration on filter paper strips.

\section{Rhizobia in field application}

The use of rhizobia as the potential alternative for chemical fertilizers has gained importance worldwide. The growth promotive effects of rhizobia as PGPR have been reported in the literature in number of crops. Rhizobium phaseoli strains isolated from the mung bean (Vigna radiata L.) nodules on inoculation in mungbean crop increased plant height $(28.2 \%)$, number of nodules per plant $(71.4 \%)$, plant biomass $(61.2 \%)$, grain yield $(65.3 \%)$, and grain nitrogen concentration (22.4\%) compared with untreated control (Zahir et al., 2010). Yadav et al., (2010) observed PGPR activity in rhizobial isolate BHUPSB02 which produced highest root dry weight $(7.5 \mathrm{mg} /$ plant) followed by BHUPSB04 (7.3 mg/plant), BHUPSB 13 (6.5 $\mathrm{mg} / \mathrm{plant})$ and BHUPSB17 (6.3 $\mathrm{mg} /$ plant) in comparison to control and other isolates.

Rajpoot and Parmar (2013) isolated three different strains of rhizobia and used them as inoculum for mungbean crop. They observed a significant increase in plant height of inoculated plant over uninoculated control. Inoculation of rhizobia as a biofertilizer on fenugreek plants improved the growth of plants in all parameter as root and shoot 
lengths, seedling fresh weights, number of nodules and number of leaves. Khaitov et al., (2016) investigated the effect of Rhizobium in chick pea plant grown under high salinity and arid conditions and they observed that inoculation of plants with strains Rhizobium significantly increased shoot, root dry matter, and nodule number by 17, 12 and $20 \%$ respectively. Tena et al., (2016) reported that application of Rhizobium strain Lt 29 and Lt 5 enhanced seed yield 59 and $45 \%$ over uninoculated control.

\section{References}

Adnan, M., Shah, Z., Saleem, N. and Shah, S.R.A. (2016) Isolation and evaluation of summer legumes rhizobia as PGPR.Pure and Applied Biology, 5, 127-133.

Alikhani, H.A. and Yakhchali B. (2009) Potential use of Iranian rhizobial strains as plant growth promoting rhizobacteria (PGPR) and effects of selected strains on growth characteristics of wheat, corn and alfalfa. Desert, 14, 27-35.

Alikhani, H.A., Rastin, N.S. and Antoun, H. (2006) Phosphate solubilization activity of rhizobia native to Iranian soils. Plant and Soil, 287, 35-41.

Arora, N.K., Kang, S.C. and Maheshwari D.K. (2001) Isolation of siderophore-producing strains of Rhizobium meliloti and their biocontrol potential against Macrophomina phaseolina that causes charcoal rot of groundnut. Current Science, 81, 673-677.

Berrada, H., Nouioui, I., Gtrai, M. and Benbrahim, K.F. (2012) Phenotypic and genotypic characterization of rhizobia isolated from root nodules of multiple legume species native of Fez, Morocco. African Journal of Microbiology Research, 6, 5314-5334.

Bhargava, Y., Murthy, J.S.R., Kumar, T.V.R. and Rao, M.N. (2016) Phenotypic, stress tolerance and plant growth promoting characteristics of rhizobial isolates from selected wild legumes of semiarid region,
Tirupati, India. Advances in Microbiology, 6, 1-12.

Bhattacharya, P.N. and Jha, D.K. (2012) Plant growth promoting rhizobacteria (PGPR). In: Emergence in agriculture. World Journal of Microbiology and Biotechnology, 1-24.

Bhattacharyya, R. N. and Basu P.S. (1997) Bioproduction of indole acetic acid by a Rhizobium sp. from the root nodules of Desmodium gangeticum. Acta Microbiologicaet Immunologica Hungarica, 44, 109-118.

Breedveld, M.W., Zevanhuizen, L.P.T.M. and Zahnder, A.B. (1991) Osmoticallyregulated trehalose accumulation and cyclic data $\beta$-glucan excretion by Rhizobium leguminosarum bv. Trifoli TA-1. Archives of Microbiology, 501506.

Chaudhary, D. and Sindhu, S.S. (2015) Inducing salinity tolerance in chickpea (Cicer arietnum L.) by inoculation of 1aminocyclopropane-1-carboxylic acid deaminase containing Mesorhizobium strains. African Journal of Microbiology Research, 9, 117-124

Dardanelli, M.S., Gonzales, P.S., Bueno, M.A. and Garcia, M.B. (2009) Effects of peanut rhizobia on the growth and symbiotic performance of Arachis hypogea under abiotic stress. Symbiosis, 47, 175-180.

Datta B. and Chakrabartty, P.K. (2014) Siderophore biosynthesis genes of Rhizobium sp. isolated from Cicer arietinum L. Biotechonology, 4, 391-401.

Datta, C. and Basu, P.S. (2000) Indole- acetic acid production by a Rhizobium species from root nodules

Duan, J., Muller, K.M., Charles, T.C., Vesely, S. and Glick, B.R. (2009) 1Aminocyclopropane-1-carboxylate (ACC) deaminase genes in rhizobia from southern Saskatchewan. Microbial Ecology, 57, 423-436.

Garg, A. and Sharma, M. (2013) Study of stress tolerant forms of rhizobia isolated from Triogenella foenumagraceum in semi-arid region of Rajasthan. International 
Journal of Science and Research, 2, 336339.

Ghosh, S. and Basu, P. S. (2006) Production and metabolism of indole acetic acid in roots and root nodules of Phaseolus mungo. Research in Microbiology, 161, 362-366.

Ghosh.S., Kumar. P.K. and Maiti, T.K. (2015) Production and metabolism of indole acetic acid in root nodules and symbiont (Rhizobium undicola) isolated from root nodule of aquatic medicinal legume Neptuniaoleracea Lour. Journal of Botany. http://dx.doi.org/10.1155/2015/ 575067

Glazer, A. and Nikaido. (2007) Microbial biotechnology. Fundamentals of applied microbiology, (2nd edition), Cambridge University press, Cambridge, New York.

Glick, B.R. (1995) The enhancement of plant growth by free living bacteria. Candian Journal of Microbiology, 109-117.

Glick, B.R. (2012) Plant growth promoting bacteria: mechanisms and applications. Hindawai Publishing Corporation, Scientifica, http://dx.doi.org/10.6064/2012/963401

Glick, R., Todorovic, B., Czarny, J., Cheng, Z., Duan, J., and McConkey, B. (2007) Promotion of plant growth by bacterial ACC deaminase. Critical Reviews in Plant Sciences, 26, 227-242.

Ivanova, S., Fedorova, E.E., Limpens, E., Mita, D.S., Genre, A. and Bonfante, P. (2012). Rhizobium- legume symbiosis shares an exocytotic pathway required for arbuscule formation. Proceeding, National Acadamy of Science, USA, 109, 83168321.

Jadhav, R.N. (2013) Isolation of rhizobia from soybean cultivated in Latur area and study of its phosphate solubilization activity. Bioscience Discovery, 4, 100-103.

Joseph, B., Patra, R.R. and Lawrence, R. (2007) Characterization of plant growth promoting rhizobacteria associated with chick pea (Cicer arietinum L.). International Journal of Plant Production, 2, 141-152.
Kassem, M., Cappelano, A. and Gounot, A.M. (1985) Impact of harsh environmental conditions on nodule formation and dinitrogen fixation of legumes. Microbiology Journal, 1, 63-75.

Kennai, A., Assefa, F. and Prabu, P.C. (2010) Characterization of acid and salt tolerant rhizobial strains isolated from faba bean fields of Wollo, Northern Ethopia. Journal of Agricultural Science and Technology, 12, 365-376.

Khaitov, B., Kurbonov, A., Abdiev, A. and Adilov, M. (2016) Effect of chickpea in association with Rhizobium to crop productivity and soil fertility. Eurasian Journal of Soil Science, 5, 105-112.

Khan, M.S., Zaidi, A., Wani, P.A. and Oves, M. (2009) Role of plant growth promoting rhizobacteria in remediation of metal contaminated soils. Environmental Chemistry Letter, 7, 1-19.

Khandelwal, A. and Sindhu, S.S. (2013) ACC deaminase containing rhizobacteria enhance nodulation and plant growth in cluster bean (Cyamopsis tetragonoloba). Journal of Microbiology Research, 3, 117-123.

Kulkarni, S. and Nautiyal, C. S. (2000) Characterization of high temperature tolerant rhizobia isolated from Prosopis juliflora grown in alkaline soil. Journal of General Applied Microbiology, 45, 213220.

Lorite, M., Munoz., Soto, Ma and Sanjuan (2010) Characterization of strains unlike Mesorhizobium loti that nodulates Lotus spp. in saline soils of Granada, Spain. Applied Environmental Microbiology, 76, 4019-4026.

Ma, W., Guinel, F.C. and Glick, B. R. (2003) Rhizobium leguminosarum biovarviciae 1-aminocyclopropane-1-carboxylate deaminase promotes nodulation of pea plants. Applied and Environmental Microbiology, 69, 4396-4402.

Maatallah, J., Berraho, E., Sanjuan, J. and Lluch, C. (2002) Phenotypic characterization of rhizobia isolated from chickpea (Cicer arietinum) growing in 
Moroccoan soils, Journal of Applied Microbiology, 93, 531-540

Mandal, S.M., Mondal, K.C., Dey, S and Pati, B.R. (2007) Optimisation of cultural and nutritional conditions for indole -3-acetic acid (IAA) production by Rhizobium sp. isolated from root nodule of Vigna mungo (L.). Research Journal of Microbiology, 2, 239-246.

Marques, P.G.C., Helena, O.S.S. and Castro, P.M.C. (2010) Assessment of the plant growth promotion abilities of six bacterial isolates using Zea mays as indicator plant. Soil Biology and Biochemistry, 42, 12291235 .

Marra, L.M., Oliveira-de, S.M. and Moreira-de, F.M.S. (2013) Solubilisation of inorganic phosphates by inoculant strains from tropical legumes. Scientia Agricola, 68, 603-609.

Marsh, L.E., Baptiste, R.B., Marsh, D.B., Trinklein, D. and Kremer, R.J. (2006) Temperature Effects on Bradyrhizobium spp. growth and symbiotic effectiveness with pigeonpea and cowpea. Journal of Plant Nutrition, 29, 331-346.

Mrkkovacki, N. and Milic, V. (2001) Use of Azotobacter chrooccum as a potential useful in agriculture alication. Annals of Microbiology, 51, 145-158.

Nagoma, L, Esau, B and Babalola, O.O. (2013) Isolation and characterization of beneficial indigenous endophtic bacteria for plant growth promoting activity in Molewane Farm, South Africa. African Journal of Biotechnology, 12, 4105-4114.

Nagoma, L, Mogatlanayane, K and Babalola, O.O. (2014) Screening of endophytic bacteria towards the development of cottage industry. Journal of Human Ecology, 47, 45-63.

Nagoma, L., Babalola, O.O. and Ahmad, F. (2012) Ecopysiology of plant growth promoting bacteria. Scientific Research and Essays, 7, 4003-4013.

Nascimento, F.X., Brıgido, C., Glick, B.R., S. Oliveira, S and Alho L. (2012) Mesorhizobium cicero LMS1expressinganexogenous 1 aminocyclopro pane-1-carboxylate (ACC) deaminase increases its nodulation abilities and chickpea plant resistance to soil constraints" Letters in Applied Microbiology, 55, 15-21.

Neilands, J.B. (1981) Iron absorption and transport of microorganisms. Annual Review of Nature. 1, 27-46.

Nithyakalyani, V., Kannan, M. and Anandan, R. (2016) Insecticide and salt tolerance of plant growth promoting root nodule bacteria. International Journal of Current Microbiology and Applied Sciences, 5, 942-956.

Othman, H. and Tamimi, S.M. (2016) Characterization of rhizobia nodulating faba been plants isolated from soils of Jordan for plant growth promoting activities and $\mathrm{N} 2$ fixation plants. International Journal of Advanced Research and Biological Sciences, 3, 2027.

Popp, C. and Off, T. (2011) Regulation of signal transduction and bacterial infection during root nodule symbiosis. Current Opinonin Plant Biology, 14, 458- 467.

Rajpoot, P and Panwar, K.S. (2013) Isolation and characterization of rhizobia and their effect on Vigna radiata. Plant Octa Journal of Biosciences, 1, 69-76.

Reddy, P.P. (2013) Plant growth promoting rhizobacteria (PGPR) Recent advances in crop protection. Springer, India, pp 131145.

Roy, M. and Basu, P.S. (2004) Studies on root nodules of leguminous plants bioproduction of indole acetic acid by Rhizobium sp. from a Twiner Clitoreaternatea. Acta Biotechnology, 12, 453-460.

Santner, A., Calderon-Villalobos, L.I.A and Estelle, M. (2006) Plant hormones are versatile chemical growth regulators of plant growth. Nature of Chemical Biology, 8, 301-307.

Schultze, M., and Kondorosi, A. (1998) Regulation of symbiotic root nodule development. Annual Review of Genetics, $32,33-57$. 
Singh N.K., Luthra, U. and Desai, N. (2013) Phenotype and genotypic characterization of Rhizobium species isolated from root nodules of Sesbania sesban found in Mumbai and its suburban areas. Indian Journal of Applied Research, 3, 60-67.

Singh, S., Gupta, G., Khare, E., and Arora, N.K. (2014) Phosphate solubilizing rhizobia promote growth of chickpea under buffering conditions. Journal of Pure and Applied Microbiology, 2, 97-106.

Spaepen, S., Vanderleydens, J. and Remans, R. (2007) Indole -3-acteic acid in microbial and microorganism-plant signaling. FEMS Microbiology Review, 31, 45-448.

Sridevi, M and Mallaiah, K.V. (2007) Production of catechol-type of siderophores by Rhizobium strains from Sesbania sesban (L.) Merr. Asian Journal of Biological Sciences, 3, 187-194.

Tena, W., Meskel, E.W. and Walley F. (2016) Symbiotic efficiency of native and exotic Rhizobium strains nodulating Lentil (Lens culinaris Medik.) in Soils of Southern Ethiopia. Agronomy, 6, 242-250.

Tsakelova, E.A., Klimova, S.Y. and Netrusov, A.I. (2005) Auxin production by bacteria associated with orchid roots. Microbiology, 74, 46-53.

Tsakelova, E.A., Klimova, S.Y. and Netrusov, A.I. (2006) Microbial producers of plant growth stimulators and their practical use. Applied Biochemistry and Microbiology, 42, 117-126.

Udvardi, M. and Poole, P.S. (2013) Transport and metabolism in legume-rhizobia symbioses. Annual Review of Plant Biology, 64, 781-805.

Verma V., Joshi K. and Mazumdar B. (2011) Study of siderophore formation in noduleforming bacterial species. Research Journal of Chemical Sciences, 2, 26-29.

Waheed, A., Afzal, A., Sultan, T. and Shah A. (2014) Isolation and biochemical characterization of Rhizobium from pea crop at Swabi. International Journal of Biosciences, 4, 231-240.

Werner, D. and Newton, W.E. (2005) Nitrogen fixation in agriculture, forestry, ecology, and the environment, Springer Netherlands, Netherlands.

Wright, W. H. "Isolation and Identification of the Siderophore "Vicibactin" Produced by Rhizobium leguminosarum ATCC 14479." (2010) Electronic Theses and Dissertations. Paper 1690.http://dc.etsu. edu/etd/1690

Zaidi, A., Khan, M.S. and Oves, M (2009) Plant growth promotion by phosphate solubilizing bacteria. Acta Microbiology Immunology, 56, 263-284.

\section{How to cite this article:}

Monika, Shashikala and Leela Wati. 2018. Biofertilizers: Potential Candidate for Sustainable Agriculture. Int.J.Curr.Microbiol.App.Sci. 7(03): 2839-2851.

doi: https://doi.org/10.20546/ijcmas.2018.703.327 